\title{
Hydrographic and Satellite Observations of Summertime Upwelling in the Taiwan Strait: A Preliminary Description
}

Jianyu $\mathrm{Hu}^{1,2, *}$, Hiroshi Kawamura ${ }^{2}$, Huasheng Hong ${ }^{3}$, Masateru Suetsugu ${ }^{2}$, and Mingsen Lin $^{4}$

(Manuscript received 7 November 2000, in final form 9 April 2001)

\begin{abstract}
Combination of the hydrographic and satellite-derived Sea Surface Temperature (SST) data provides new evidence for the existence of four upwelling-related Low Temperature Zones (LTZs) in the Taiwan Strait in summer. These LTZs are located along the southwestern coast of the Taiwan Strait (SW-LTZ), along the northwestern coast of the Taiwan Strait (NW-LTZ), near the Taiwan Bank (TB-LTZ) and around the Penghu Islands (PH-LTZ), respectively. The hydrographic data from three August cruises during 1997-1999 show that these LTZs also possess relatively higher salinity (greater than 34) at the surface layer. Four years of higher resolution AVHRR satellite-derived SST data clearly indicate the summertime pattern of these upwelling-related LTZs and demonstrate their inter-annual and inter-monthly variability.
\end{abstract}

(Key words: Upwelling, Variability, Taiwan Strait, Hydrographic data, Satellite-derived SST data, Summer)

\section{INTRODUCTION}

The Taiwan Strait plays a very important role on the water exchange between the East China Sea and the South China Sea. As shown in Fig.1, the northern boundary of the Taiwan Strait is usually defined as the line between Pingtan (or Ping- $t$ 'an, Hai-t'an Tao, Haitan Island) and Fuguijiao (Fu-kuei Chiao), and the southern boundary between Dongshan (Tung shan) and Maobitou (Mao-pi T'ou). The Taiwan Strait has a complex bottom topography, in which the depth is less than $50 \mathrm{~m}$ along Fujian (Fu-chien) coast and is about $40 \sim 80 \mathrm{~m}$ in the northern

\footnotetext{
${ }^{1}$ Marine Environmental Laboratory of Ministry of Education; Institute of Subtropical Oceanography, Xiamen University, Fujian 361005, China

${ }^{2}$ Center for Atmospheric and Oceanic Studies, Faculty of Science, Tohoku University, Sendai 980-8578, Japan

${ }^{3}$ Marine Environmental Laboratory of Ministry of Education, Xiamen University, Fujian 361005, China

${ }^{4}$ State Satellite Ocean Application Service, Beijing 100081, China

* Corresponding author address: Jianyu Hu, Institute of Subtropical Oceanography, Xiamen University, Fujian 361005, China; E-mail: hujy@xmu.edu.cn
} 


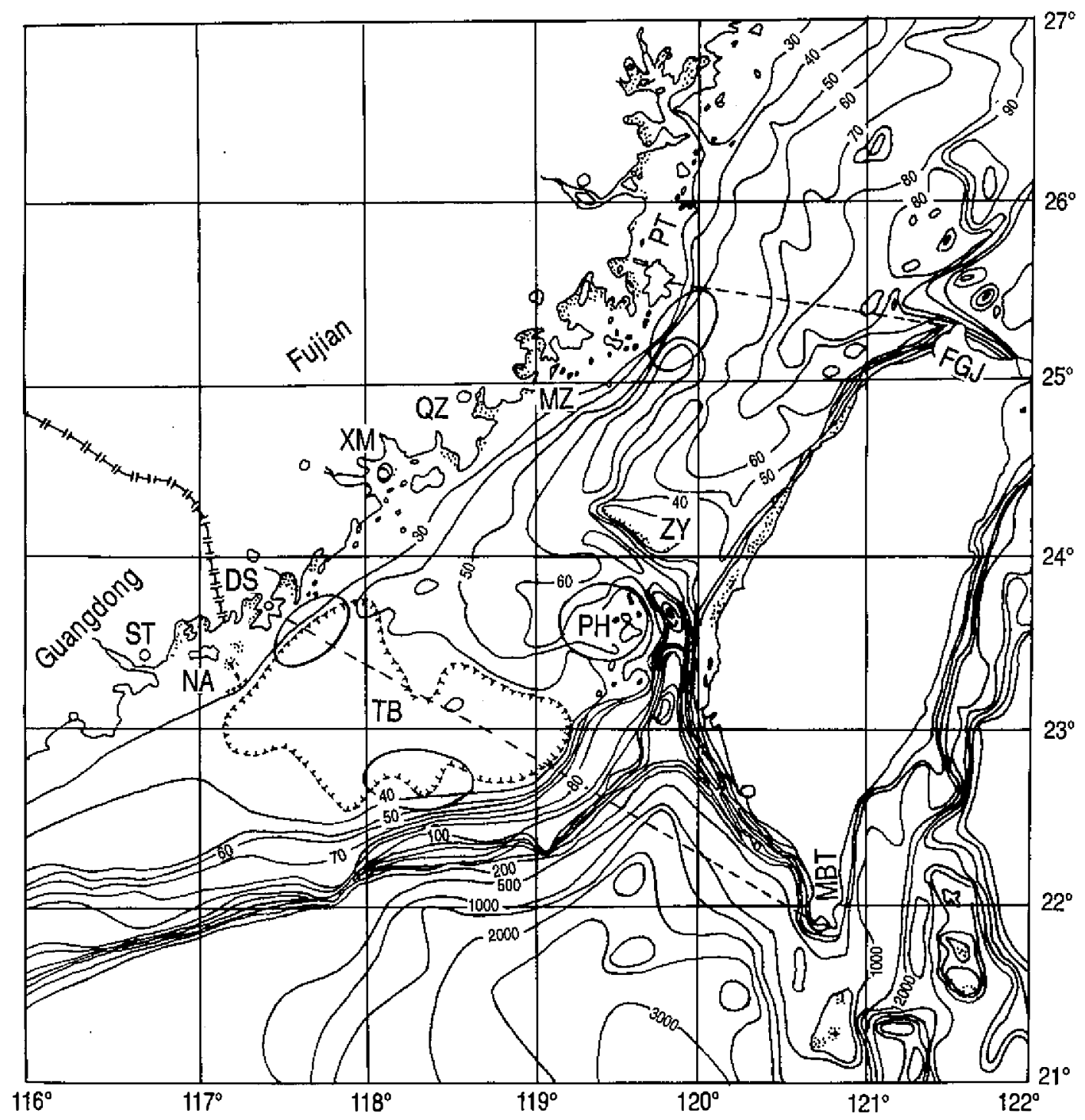

Fig. 1. Map of the Taiwan Strait with bottom topography. Four ellipses or circles in the figure schematically denote 4 upwelling regions in the Taiwan Strait. Dashed lines show the schematic boundaries of the Taiwan Strait. DS, FGJ, MBT, MZ, NA, PH, PT, QZ, ST, TB, XM and ZY in the figure denote Dongshan (or Tung Shan), Fuguijiao (Fu-kuei Chiao), Maobitou (Mao-pi T'ou), the Meizhou Island (Mei-chow Tao), Nan-ao (Nan Ao), the Penghu Islands (P'eng-hu Is.), Pingtan (Ping-t'an), Quanzhou (Chuanchow), Shantou (Shan-t'ou), the Taiwan Bank (Tai-wan Bank), Xiamen (Hsia-men) and the submarine Zhangyun Ridge (Chang-yun Ridge), respectively. The depth contours are in meter. 
and central parts of the Taiwan Strait. As for the southern Taiwan Strait, a shallower area is located in the Taiwan Bank (or Taiwan Shoal) with a depth of less than $20 \mathrm{~m}$.

$\mathrm{Wu}$ (1983) demonstrated a climatological picture of the summertime (June-August) temperature and salinity distributions (Fig. 2) and concluded that: the Sea Surface Temperature (SST) ranges from $25^{\circ} \mathrm{C}$ to $30^{\circ} \mathrm{C}$ with lower SST in the northwestern and southwestern parts and higher SST in the southern and eastern parts of the Taiwan Strait (Fig. 2a), and the Sea
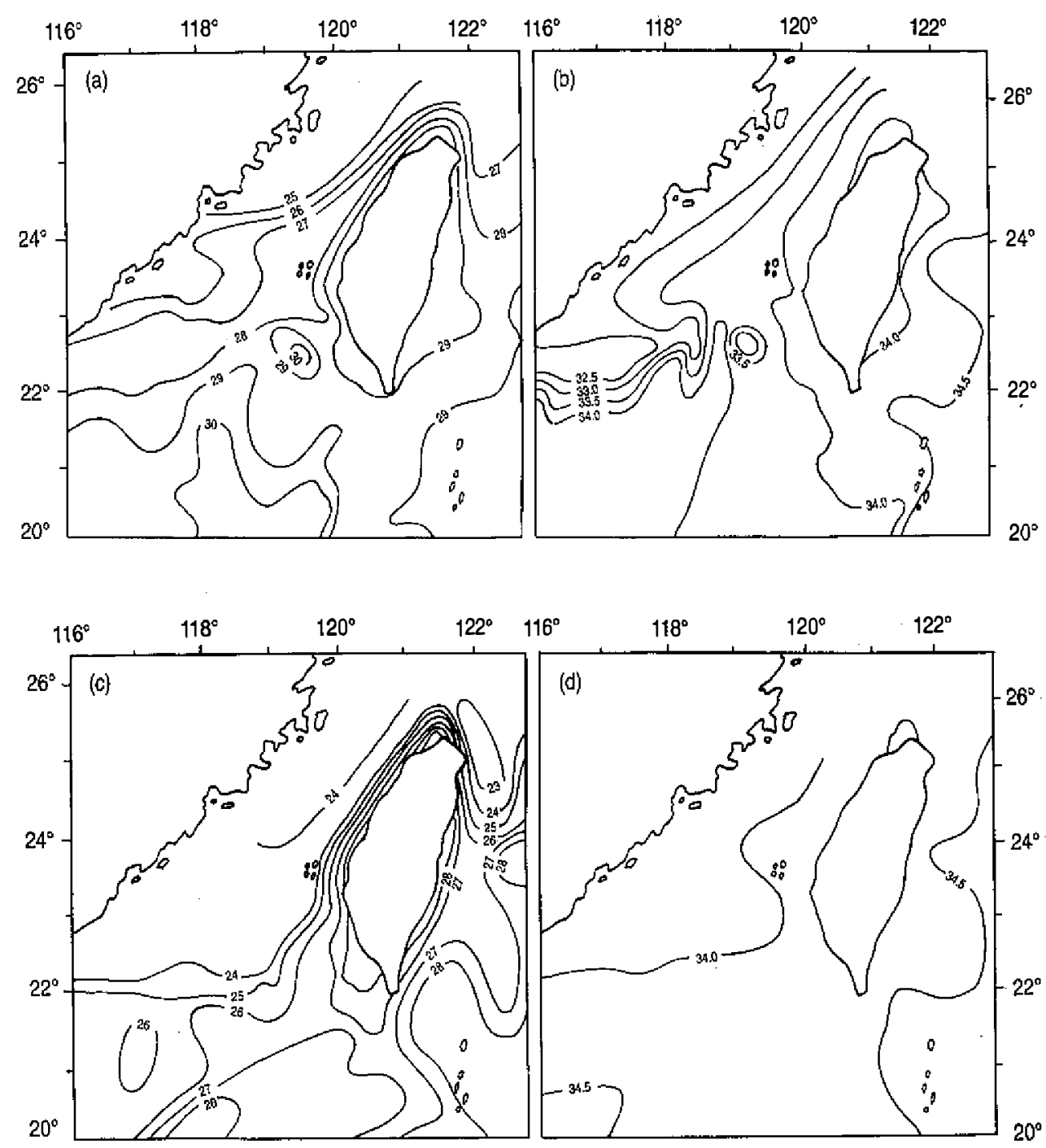

Fig. 2. Temperature and salinity distributions in the Taiwan Strait in summer (June-August). (a) Sea surface temperature, (b) sea surface salinity, (c) temperature at $50 \mathrm{~m}$ layer and (d) salinity at $50 \mathrm{~m}$ layer. Redrawn after $\mathrm{Wu}(1983)$. 
Surface Salinity (SSS) is higher in the eastern part but lower in the western part of the Taiwan Strait while a low SSS tongue extends to the Taiwan Bank from the eastem Guangdong (Kuangtung) (see Fig. 2b). Both temperature and salinity are spatially homogeneous, with a lower temperature of about $24^{\circ} \mathrm{C}$ and a higher salinity of about 34 , at the $50 \mathrm{~m}$ depth of the entire Taiwan Strait (Figs. 2c and d). Obviously, since the upwelling brings the deeper water to the upper layer, the surface layer is usually characterized with relatively lower temperature and higher salinity features, which become important indicators for existence of the upwelling.

As reviewed by Hu et al. (2000), there exist four main upwelling regions (see Fig.1 for schematic locations) in the Taiwan Strait. They are located along the southwestern coast of the Taiwan Strait (called SW-upwelling region hereafter), along the northwestern coast of the Taiwan Strait (NW-upwelling region), near the Taiwan Bank (TB-upwelling region) and around the Penghu Islands (PH-upwelling region). They are generally considered as being induced by the ascending of the northward or northeastward near-bottom currents and the influence of the southwest monsoon.

This paper presents some new observational evidence for the existence of these upwelling regions and describes their variability in summer. Section 2 provides some evidence using recent hydrographic observations. Section 3 focuses on the variability of the upwelling regions with use of the high resolution satellite-derived SST data. A summary is given in Section 4.

\section{RECENT HYDROGRAPHIC OBSERVATIONS}

Recently, three August cruises were jointly conducted by Xiamen University and Fujian Institute of Oceanology of China during 1997-1999. The sampling stations for each cruise are denoted in Figs. 3a, b and c, respectively. During these cruises, temperature and salinity were measured using the SBE 19 CTD Profiler. The underway measurements of SST and SSS were also carried out along the sailing tracks using the SBE 21 Thermosalgraph in the cruises of August 1998 and 1999. These recent cruise data provide some new hydrographic evidence for the upwelling in the Taiwan Strait. Since the cruises did not cover the area near the Penghu Islands (or P'eng-hu Is.), we can only describe the evidence for three of the upwelling regions, not including the PH-upwelling region as once studied or mentioned by Fan $(1979,1982)$, Hung et al. (1986), Wang and Chern (1992a, 1992b), Weng et al. (1992), Chen and Tang (1993), Jan et al. (1994a), and etc.

\subsection{New Hydrographic Evidences for the SW-upwelling Region}

As shown in Fig. 4, the sectional temperature and salinity distributions indicate a Low Temperature and High Salinity (LTHS, here refers to the water with temperatures less than $24^{\circ} \mathrm{C}$ and salinity greater than 34) feature in the lower layer of Station 9709 (southeast of Nanao) in August 1997. In addition, both isotherm and iso-salinity curves were uplifted so as to make the surface layer near Station 9709 become a Low Temperature Zone (LTZ, schematically denoted by a circle in Fig. $3 \mathrm{a}$ ), which is regarded here as having at least $2^{\circ} \mathrm{C}$ SST difference between cold core and its surroundings and also having SSS of about 34. The SST at 

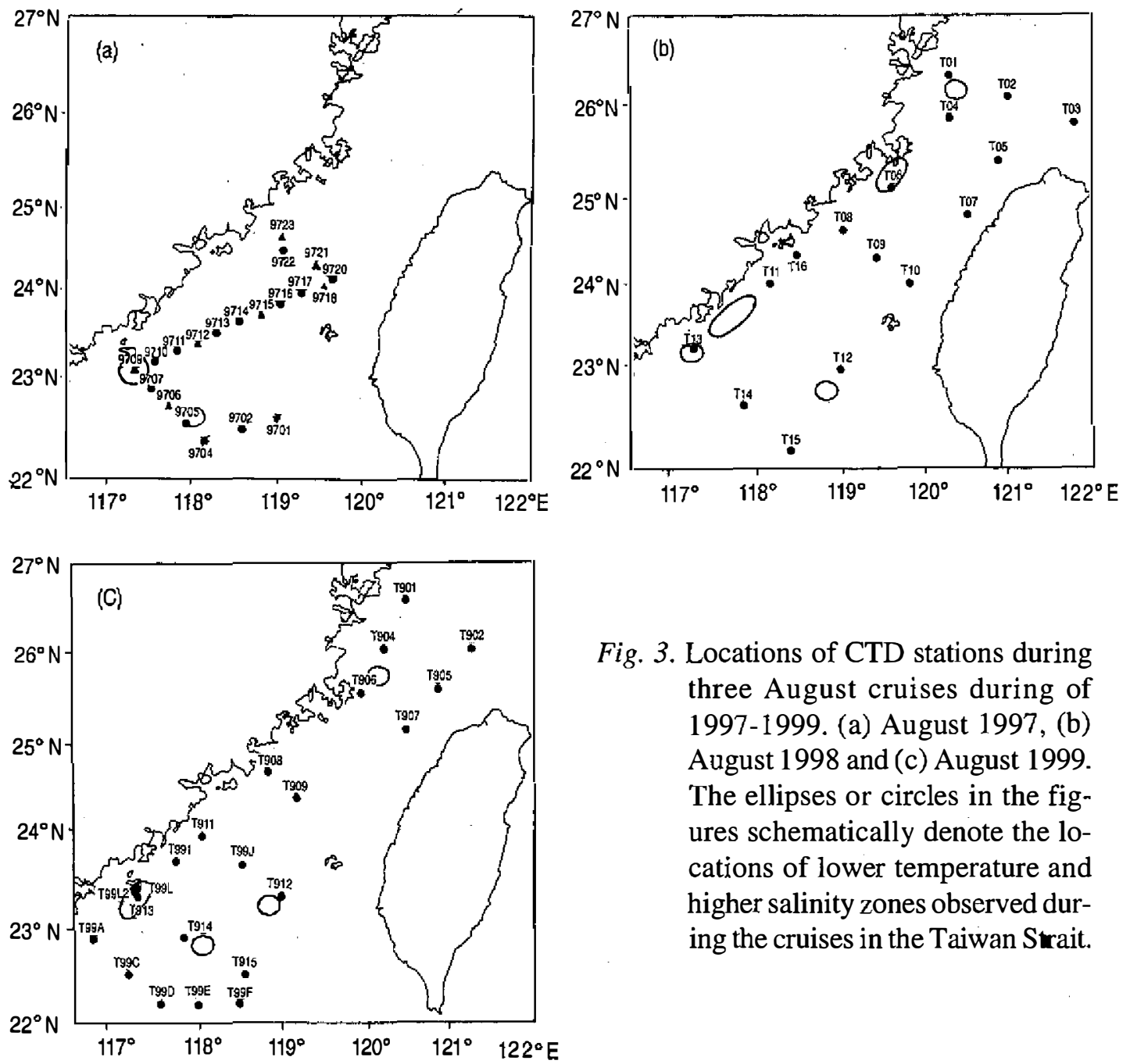

Fig. 3. Locations of CTD stations during three August cruises during of 1997-1999. (a) August 1997, (b) August 1998 and (c) August 1999. The ellipses or circles in the figures schematically denote the locations of lower temperature and higher salinity zones observed during the cruises in the Taiwan Strait.

Station 9709 was $25.4^{\circ} \mathrm{C}$, about $2^{\circ} \mathrm{C}$ lower than that in its surroundings.

Figure 5 illustrates the SST and SSS curves measured underway along Section T11-T13 between Xiamen and Nan-ao in August 1998. It is obvious from Fig. 5 that the SSS varies between $34.2 \sim 34.5$, indicating a high salinity feature along the section. However, two LTZs, being separated by a relatively higher temperature zone, are identified along the southwestern coast of the Taiwan Strait (shown in two ellipses in Fig. 3b). One is located in the east of Dongshan with the length of about $60 \mathrm{~km}$ and the SST of only $23.5^{\circ} \mathrm{C}$. Another appears near Nan-ao (Station T13) also with obvious low temperature feature (SST: $23.5^{\circ} \mathrm{C}$ ). The SST differences between these two LTZs and their surroundings are $2 \sim 4^{\circ} \mathrm{C}$.

As for the cruise of August 1999, an LTZ was identified near Nan-ao in the SST distribution (Fig. 6) with the core SST of less than $24^{\circ} \mathrm{C}$. Moreover, the sectional temperature and salinity distributions showed that the LTHS water appeared at the lower layer in the southwest 

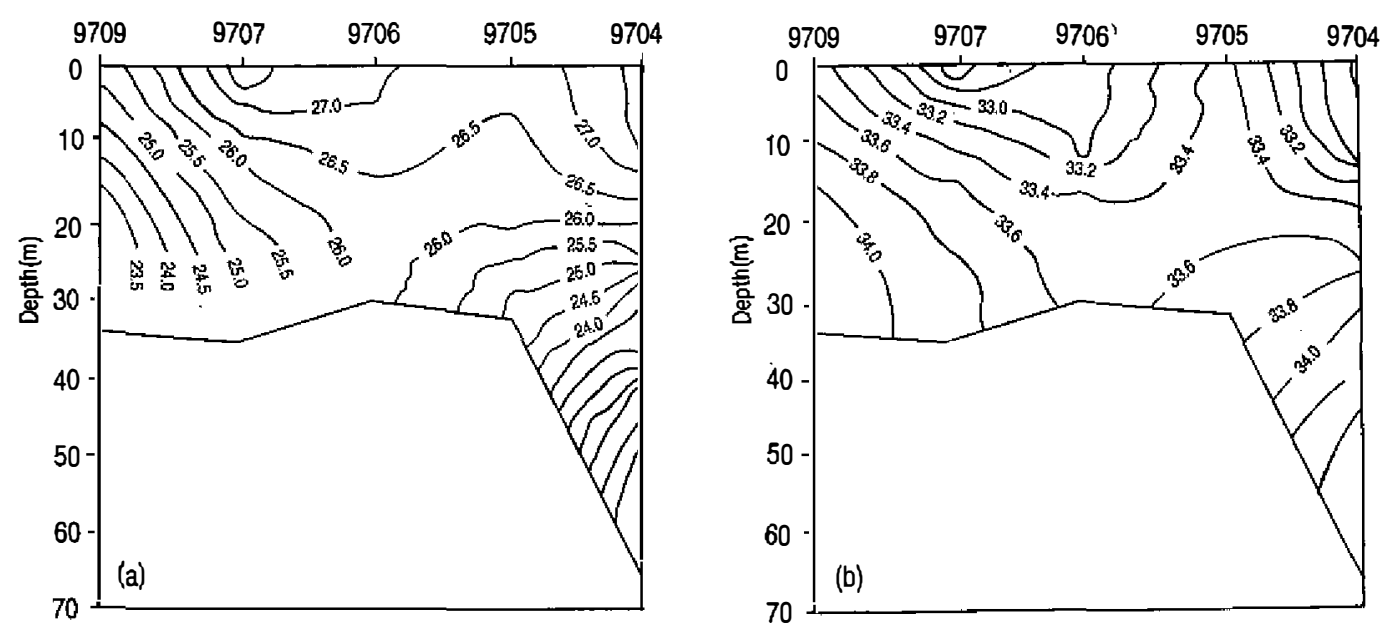

Fig. 4. Sectional temperature (a) and salinity (b) distributions at Section 97099704 during the cruise of August 1997.

of Nan-ao, ranging from Station T99A to T99L, and had a tendency to climb towards the upper layer.

Obviously, these cruise data respectively indicate one or two LTZs at the surface layer along the southwestern coast of the Taiwan Strait. These LTZs, with higher salinity, had different scale, location and feature at each cruise. As discussed by Chen et al. (1982), the existence of LTZ along the southwestern coast of the Taiwan Strait can not be explained by local river discharge, summertime surface current and net heat flux. These LTZs, sometimes with the SST even lower than $23.5^{\circ} \mathrm{C}$, may be caused by the upwelling because the summertime southwest winds are beneficial for inducing the upwelling near the coast (Cai and Lennon 1988; Li and Li 1989; Zhang et al. 1991; Hong et al. 1991; Jan et al. 1994b; Wu et al. 1997; Yan et al. 1997).

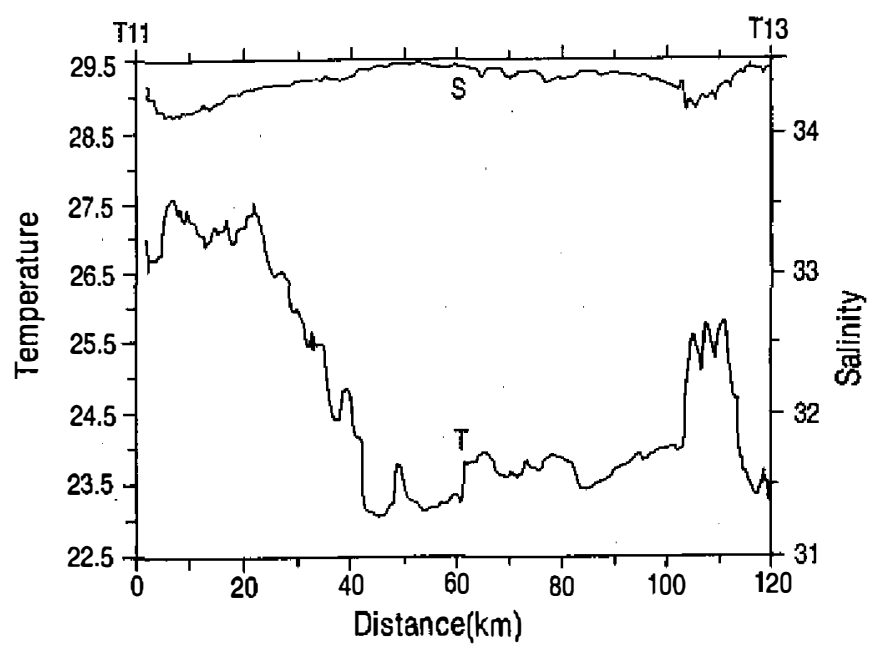

Fig.5. Underway measurements of sea surface temperature $(\mathrm{T})$ and salinity $(\mathrm{S})$ along Section T11-T13 during the cruise of August 1998. 


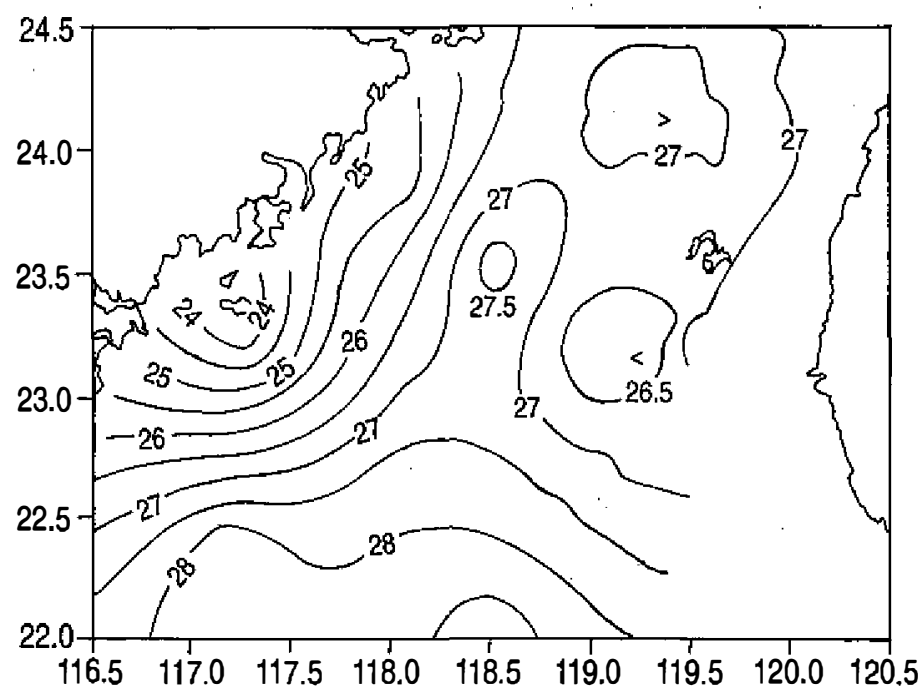

Fig. 6. Distribution of sea surface temperature during the cruise of August 1999.

\subsection{New Hydrographic Evidence for the NW-upwelling Region}

During the cruise of August 1998, an obvious LTZ was captured south of Pingtan by the underway measurements of SST and SSS along Section T04-T16. Figure 7 indicates that it was centered near Station T06, in which the core SST is about $25^{\circ} \mathrm{C}$, about $2 \sim 3^{\circ} \mathrm{C}$ lower than that in its surroundings, and the SSS is about 34.2. Another two relatively lower SST zones appeared between Station T06 and T16, but the SST differences between cold cores and their surroundings were only about $1 \sim 1.5^{\circ} \mathrm{C}$. Meanwhile, one more LTZ was observed between Station T01 and T04 with its cold core SST lower than $26^{\circ} \mathrm{C}$ and higher SSS about 34.0 (see Fig. $3 b$ for the location).

The underway measurements of SST and SSS along Section T908-T901 in August 1999 indicated an LTZ near Station T906 (northeast of Pingtan), with the cold core SST of $24.8^{\circ} \mathrm{C}$

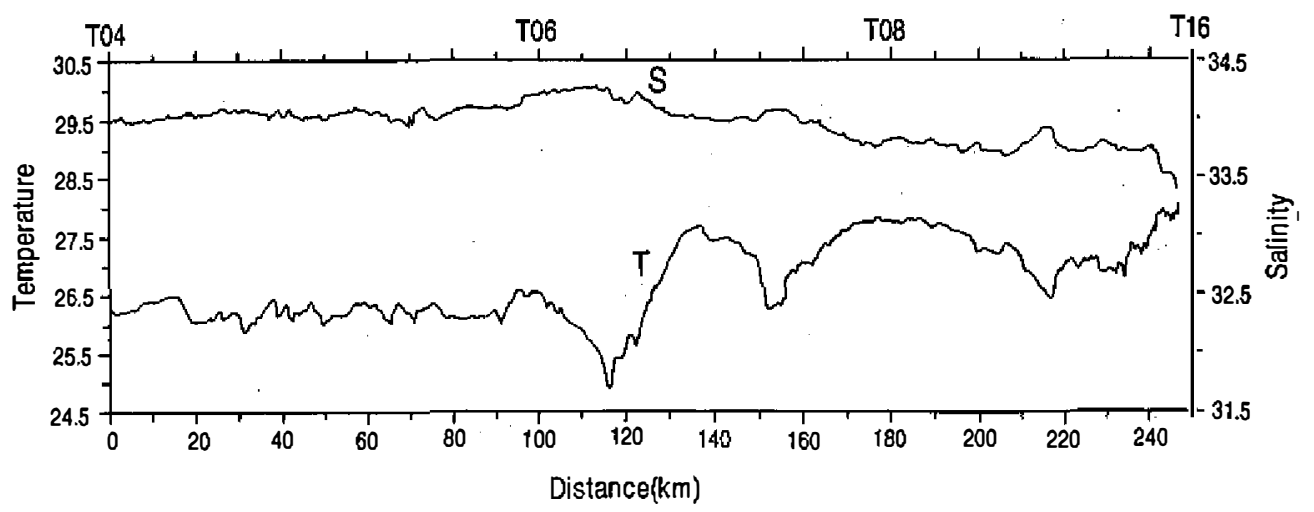

Fig. 7. Underway measurements of sea surface temperature (T) and salinity (S) along Section T04-T16 during the cruise of August 1998. 
and the SSS greater than 34.4 (Fig. 8). The sectional temperature and salinity distributions also show that the LTHS water $\left(\mathrm{T}<24^{\circ} \mathrm{C}, \mathrm{S}>34\right)$ existed in the lower layer near Station T906 and tended to climb towards the upper layer.

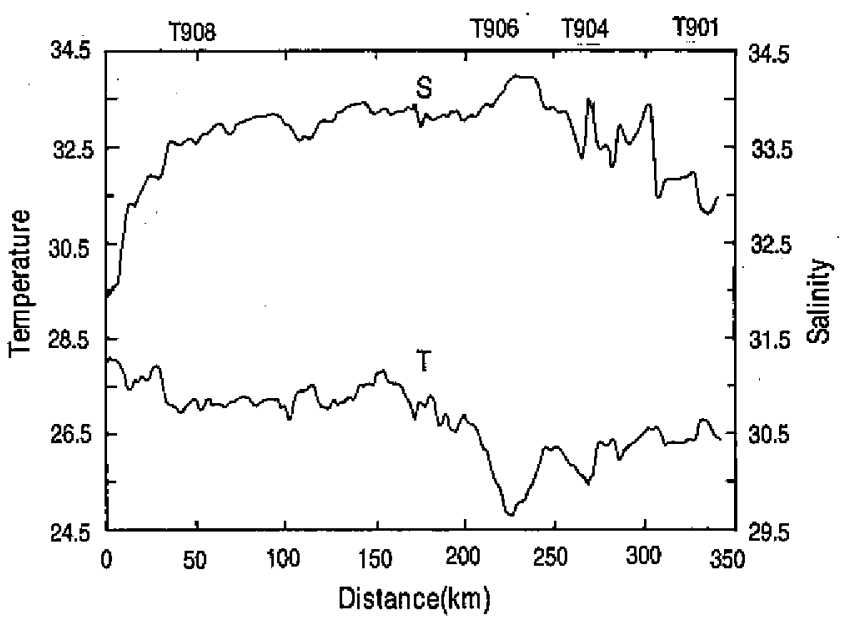

Fig. 8. Underway measurements of sea surface temperature (T) and salinity (S) along Section T908-T901 during the cruise of August 1999.

Evidently, both cruise data indicate one or two LTZs, with high SSS greater than 34, along the northwestern coast of the Taiwan Strait, especially near the coast of Pingtan. The formation of these LTZs may be attributed to the upwelling there, as reported by Xiao (1988), Weng et al. (1988), Huang $(1989,1991)$, and etc.

\subsection{New Hydrographic Evidence for the TB-upwelling Region}

Figure 4 shows that both isothermal curves and iso-salinity curves had the tendency to swell towards the upper layer near Station 9705 in August 1997. It made the surface layer near Station 9705 become a relatively lower SST and higher SSS zone (illustrated by an ellipse in Fig. 3a). However, the water with obvious LTHS feature $\left(\mathrm{T}<23^{\circ} \mathrm{C}, \mathrm{S}>34\right)$ still stayed below 40m layer of Station 9704 (south of the Taiwan Bank) as indicated by the multi-day observations there (Hu et al. 1999), suggesting that the LTHS water did not climb to the surface layer.

The underway measurements of SST and SSS were conducted along the Section T15T12 passing through the eastern Taiwan Bank in August 1998. The measurements captured an LTZ (Fig. 9) near Station T12 (see Fig. 3b for location) over the eastern Taiwan Bank. The SST is only $25^{\circ} \mathrm{C}$ and the SSS greater than 34 .

Two underway measurement sections were located near the Taiwan Bank during the cruise of August 1999. Two LTZs (Fig. 3c) were identified at the surface layer in the south of the Taiwan Bank (between Station T914 and T915 as shown in Fig.10a) and over the eastern Taiwan Bank (near Station T912 as shown in Fig.10b), respectively. The latter one, almost at the same location as that indicated in August 1998, was with the SST of about $25^{\circ} \mathrm{C}$ and SSS of about 34 .

Therefore, some LTZs can sometimes be captured at the surface layer near the Taiwan Bank, demonstrating the signal of TB-upwelling regions as reported by Chen et al. (1982), Li (1993), etc.. However, since the TB-upwelling is also affected by the tides (Hu et al. 1999; 


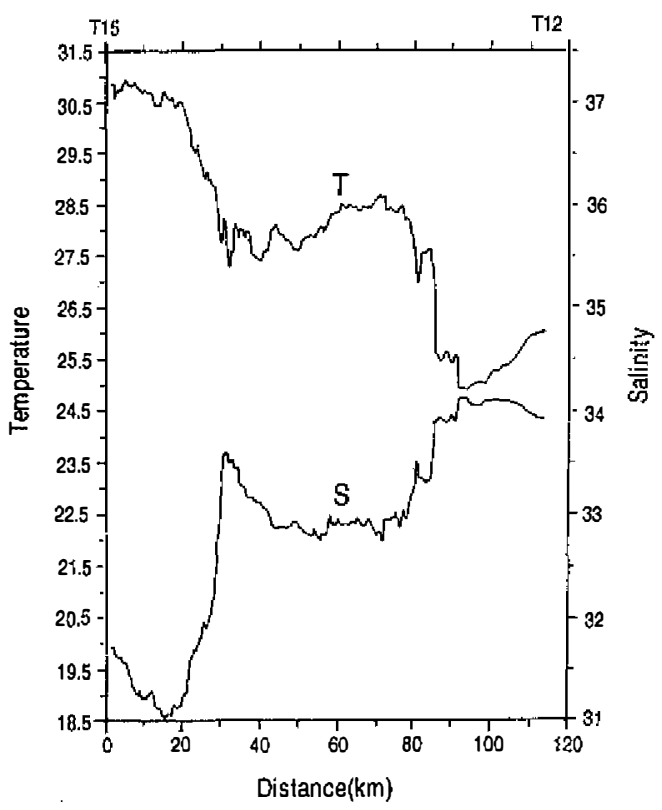

Fig. 9. Underway measurements of sea surface temperature $(\mathrm{T})$ and salinity (S) along Section T15-T12 during the cruise of August 1998.
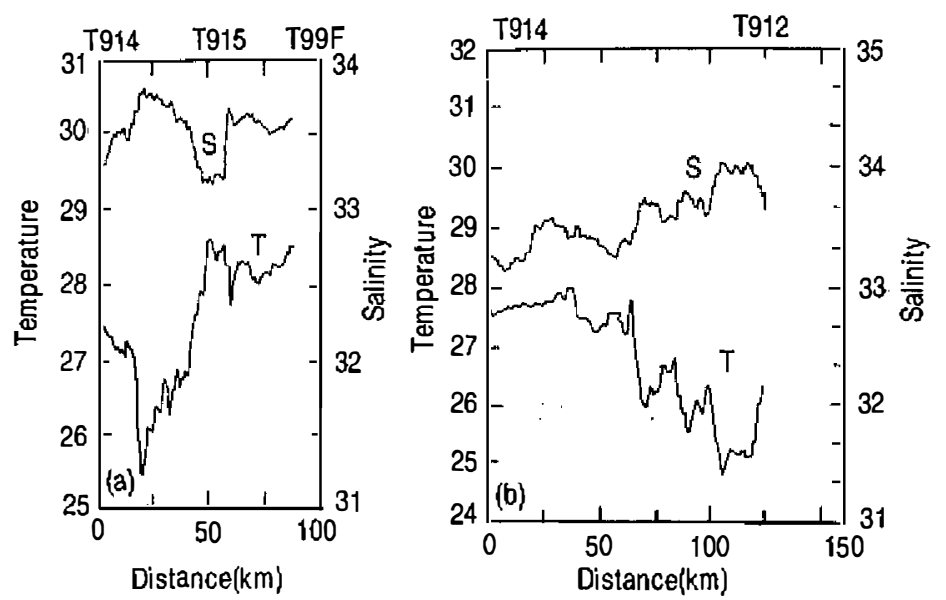

Fig. 10. Underway measurements of sea surface temperature (T) and salinity (S) along Section T914-T99F (a) and Section T914-T912 (b) during the cruise of August 1999.

Zhang et al. 2000), it is not always identified with obvious lower temperature and higher salinity feature at the surface layer.

\section{SATELLITE OBSERVATIONS USING AVHRR SST IMAGES}

Though recent hydrographic observations surely provide some new evidence for the abovementioned three upwelling regions, it is difficult to discuss the upwelling variability just on 
the basis of limited cruise data from a specific period. Fortunately, the satellite-derived SST data can serve as a good means for further understanding of the Taiwan Strait upwelling.

The NOAA-12 and NOAA-14 satellites, having a polar orbit, pass through the studied area $\left(20-27^{\circ} \mathrm{N}\right.$ and $\left.115-122^{\circ} \mathrm{E}\right)$ twice every day in descending and ascending orbits. About 1000 useful SST snapshot images were received during May-September of 1996-1999. Using the Multi-Channel SST (MCSST) algorithm (Sakaida and Kawamura 1992, 1996), the AHighers (Advanced AVHRR-based HIGHER spatial resolution SST) data set is produced by the processing system contributed by Sakaida et al. (2000). The spatial resolution of the AHighers image is $0.01^{\circ}$.

Since the SSTs are strongly affected by the diumal heating and cooling cycle, especially in summer, we deal with monthly mean or more long-term mean SST fields. Some monthly, bi-monthly and summertime SST images are thus produced for the studied area.

Figures 11, 12 and 13 show the summertime SST image, the bi-monthly SST images from 1996-1999 and the monthly SST images of June-September 1998, respectively. In order to see the negative anomalies associated with the Taiwan Strait upwelling, we subtract the spatial mean SST of the summertime, each bi-monthly and each monthly SST field from Figs. 11, 12 and 13, respectively. Investigating these images, it can be concluded that there exist four main LTZs (denoted by $-1^{\circ} \mathrm{C}$ contour lines in the figures), named as SW-LTZ, NW-LTZ, TB-LTZ

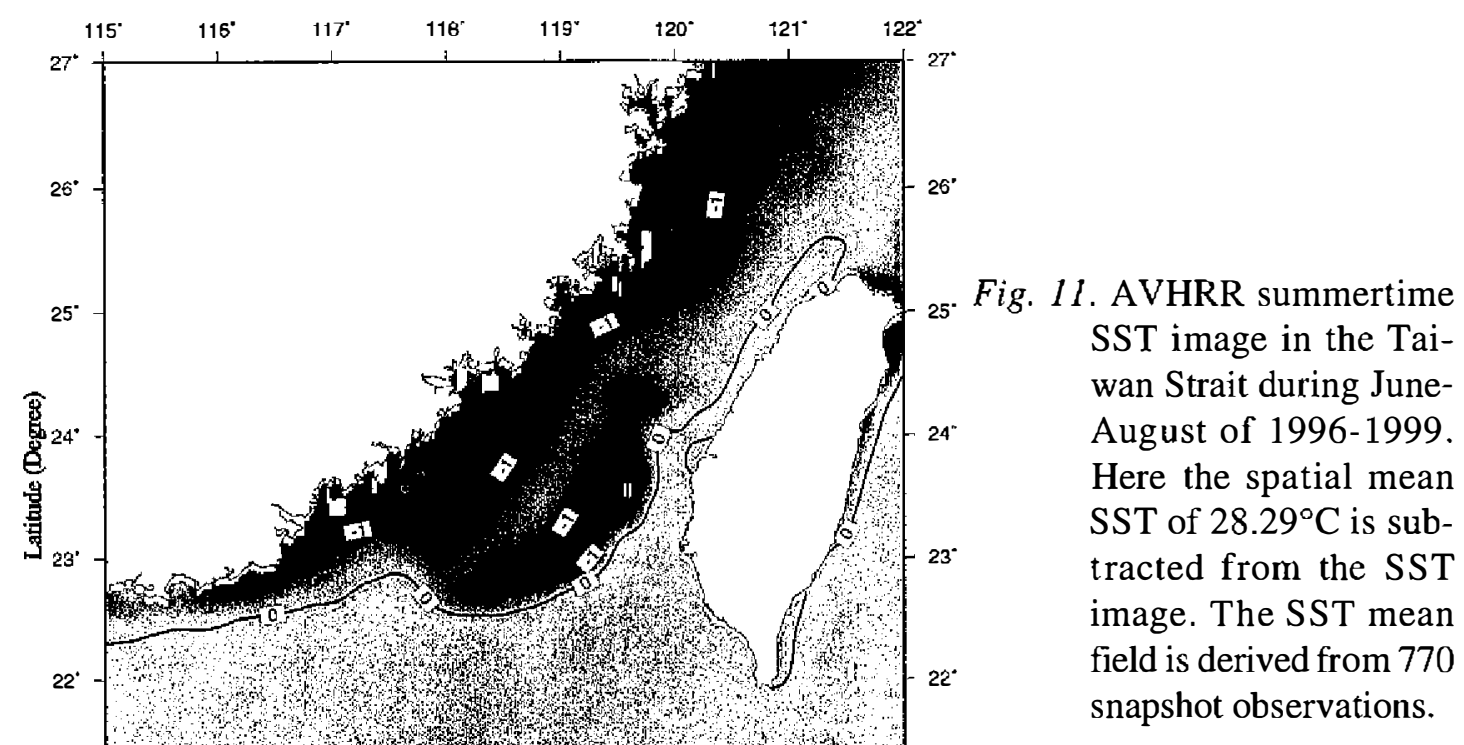



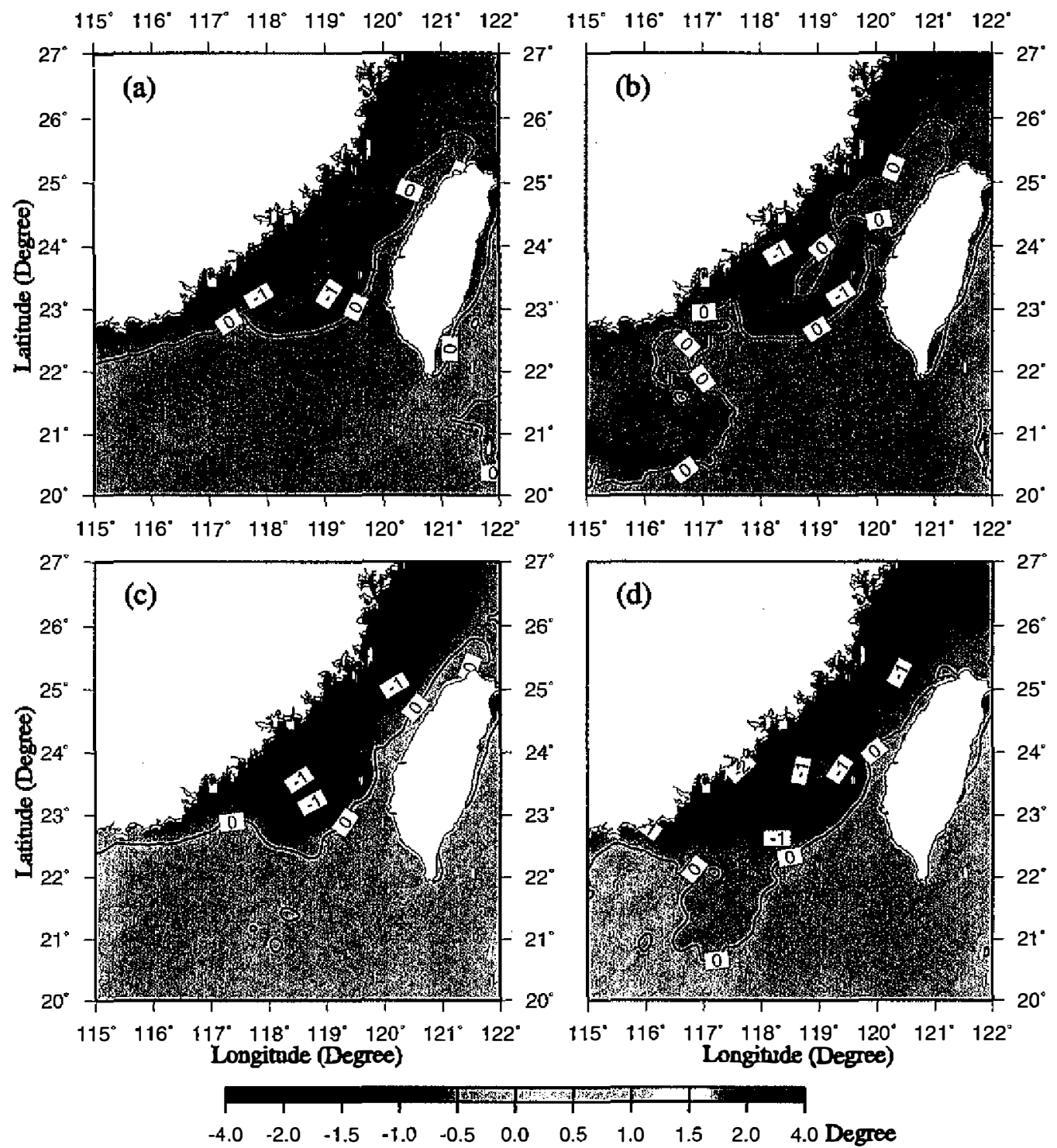

Fig.12. AVHRR bi-monthly SST images in the Taiwan Strait. (a) July-August 1996, (b) July-August 1997, (c) July-August 1998 and (d) July-August 1999. Here the spatial mean SST of $28.48^{\circ} \mathrm{C}$ (being derived from 142 observations), $28.21^{\circ} \mathrm{C}$ (57 observations), $28.78^{\circ} \mathrm{C}$ (125 observations) and $28.03^{\circ} \mathrm{C}(124$ observations) is subtracted from the SST images in (a), (b), (c) and (d), respectively.

and PH-LTZ, in the Taiwan Strait in summer. The SW-LTZ usually has two centers located in the east of Dongshan and in the southwest of Nan-ao, respectively. The NW-LTZ also centers in both northeast and southwest of Pingtan. The PH-LTZ is often seen around the Penghu 

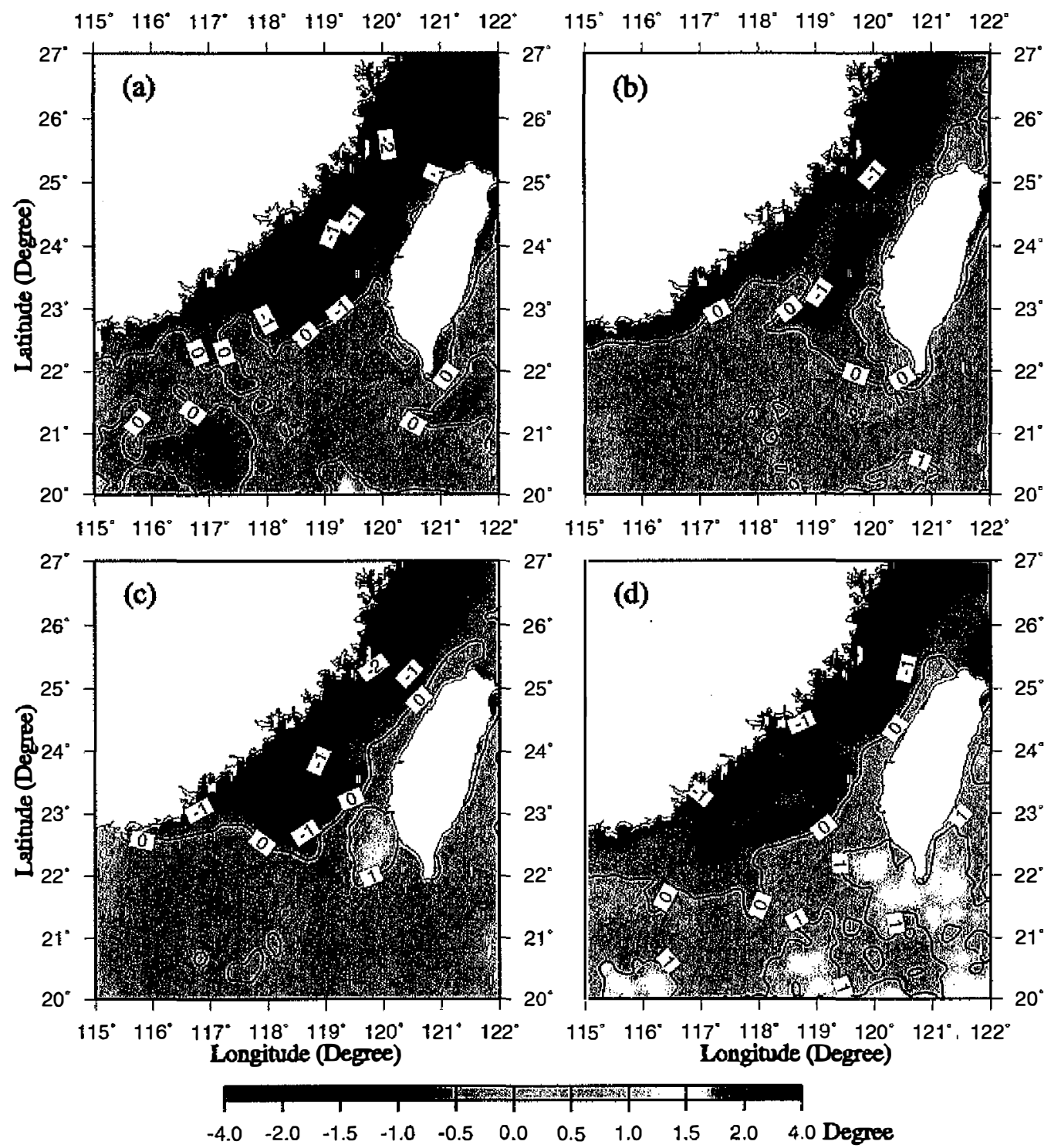

Fig.13. AVHRR monthly SST images in the Taiwan Strait. (a) June 1998, (b) July 1998, (c) August 1998 and (d) September 1998. Here the spatial mean SST of $28.47^{\circ} \mathrm{C}$ (being derived from 57 observations), $28.39^{\circ} \mathrm{C}$ (45 observations), $28.96^{\circ} \mathrm{C}$ ( 80 observations) and $27.94^{\circ} \mathrm{C}(44$ observations) is subracted from the SST images in (a), (b), (c) and (d), respectively.

Islands or in the north of the Penghu Islands. The TB-LTZ generally appears over the shallower Taiwan Bank, and it sometimes connects with the SW-LTZ at its western edge while most other time connects with the PH-LTZ at its northeastern edge. These LTZs correspond 
with the upwelling regions mentioned above and can be considered upwelling-related LTZs. Spatial and temporal scales and variability of these satellite-SST-derived LTZs are important indicators for the Taiwan Strait upwelling.

Figure 11 clearly indicates that the SW-LTZ and the NW-LTZ appear along the southwestern and northwestern coasts of the Taiwan Strait, respectively. Both the TB-LTZ and the PH-LTZ connect with each other so as to form an LTZ belt running from the southern Taiwan Bank to the north of the Penghu Islands.

The inter-annual variability of LTZs can be examined by the bi-monthly SST images in Fig.12. Appearing sizes of two LTZs, i.e., SW-LTZ and NW-LTZ, along the southwestern and northwestem coasts of the Taiwan Strait were small in 1997 but larger in both 1998 and 1999. The TB-LTZ often is connected with the PH-LTZ while it was also connected with the SWLTZ in 1999 (Fig.12d). The size of PH-LTZ was smallest in 1998 (Fig.12c). Evidently, these SST images indicate that four main LTZs, which may be caused by the corresponding upwelling, had a large inter-annual variability during 1996-1999.

Figure 13 shows four representative monthly SST images to indicate the inter-monthly variability of the LTZs in the Taiwan Strait. The image for May is not included in the comparison because the LTZ was rarely identified in May during 1996-1999. The NW-LTZ was larger during June-September (see Fig. 13), ranging from the northeast of Pingtan to the south of Meizhou Island. In the southern Taiwan Strait, the PH-LTZ was larger in June (Fig. 13a), and the TB-LTZ was connected with the PH-LTZ in July (Fig. 13b). However, the TB-LTZ merged with the SW-LTZ while the PH-LTZ was not clearly seen in August (Fig.13c). In September, only small scale SW-LTZ existed in the southem Taiwan Strait (Fig. 13d). It is also evident that these LTZs have a large monthly variability.

\section{SUMMARY}

As stated above, both hydrographic data and satellite SST data provide new evidence for the existence of four upwelling-related LTZs in the Taiwan Strait. The results of these analyses can be summarized as follows:

(1) Four main LTZs, which are considered as induced by corresponding upwelling, appear in the Taiwan Strait in summer. These LTZs are located along the southwestern coast of the Taiwan Strait (SW-LTZ), along the northwestern coast of the Taiwan Strait (NW-LTZ), near the Taiwan Bank (TB-LTZ) and around the Penghu Islands (PH-LTZ), respectively. The SW-LTZ usually has two centers located in the east of Dongshan and in the southwest of Nan-ao, and the NW-LTZ is often seen both northeast and southwest of Pingtan. The low temperature features of three LTZs were captured by the recent August cruises during 19971999. The cruise data show that these LTZs also possessed relatively higher salinity (greater than 34).

(2) Monthly or more long-term mean SST images derived from the satellite observations clearly indicate the summertime pattern of these upwelling-related LTZs and also demonstrate their inter-annual and inter-monthly variability. In the southern Taiwan Strait, the LTZs are often of quite different scale and location from June to September. Along the western coast of the Taiwan Strait, both LTZs were smaller in 1997 but larger in 1998 and 
1999.

However, since the LTZs have an inter-annual and inter-monthly variability, it is not suitable to describe or deduce the features of the corresponding upwelling just from some limited cruise data or a few satellite SST snapshot images. Meanwhile, the mechanisms for the variability still have not been well understood. Therefore, further analyses of long term high resolution and high quality SST satellite data should be undertaken in the near future. In addition, long term mooring observations and multi-disciplinary investigations will also be important for better understanding the Taiwan Strait upwelling.

Acknowledgements This research is supported by the Key Project (No. 98-Z-179) of Fujian Province of China, the Key Project (No. 49636220) of the Natural Science Foundation of China and the State Key Basic Research Program of China (No. G1999043805). The study is also supported by Research and Development Applying Advanced Computational Science and Technology, Japan Science and Technology Corporation. The research work was done during Hu's visit to the Oceanic Variation Research Section, Center for Atmospheric and Oceanic Studies, Tohoku University, Japan. Hu would like to express his sincere thanks to all the colleagues, students and crew members for their kind help in the cruise data collecting and processing. Authors are much obliged to the editor and anonymous reviewers for their useful and constructive comments which enabled them to improve the manuscript a great deal.

\section{REFERENCES}

Cai, W. J., and G. W. Lennon, 1988: Upwelling in the Taiwan Strait in response to wind stress, ocean circulation and topography. Estuarine, Coastal and Shelf Science, 26, 1531.

Chen, J. Q., Z. L. Fu, and F. X. Li, 1982: A study on upwelling in Minnan-Taiwan Shoal fishing ground. Taiwan Strait, 1(2), 5-13 (in Chinese with English abstract).

Chen, J. Y., and T. Y. Tang, 1993: Hydrographic diswibution around Taiwan. In Proceedings of the Symposium on the Physical and Chemical Oceanography of the China Seas. China Ocean Press, Beijing, 130-136.

Fan, K. L., 1979: On upwelling off the Peng-hu Islands. Acta Oceanographica Taiwanica, 9, 50-57.

Fan, K. L., 1982: A study of water masses in Taiwan Strait. Acta Oceanographica Taiwanica, 13, $140-153$.

Hong, H. S., S. Y. Qiu, W. Q. Ruan, and G. C. Hong, 1991: Minnan-Taiwan Bank fishing ground upwelling ecosystem study. In Minnan-Taiwan Bank Fishing Ground Upwelling Ecosystem Study. China Science Press, Beijing, 1-18. (in Chinese with English abstract).

Hu, J. Y., H. S. Hong, X. B. Zhang, Z. Z. Chen, C. Y. Zhang, F. Q. Lin, H. X. Liang, and J. S. Hong, 1999: Time series variation of vertical temperature and salinity distributions at two anchored stations in southern Taiwan Strait during August 1997. J. Xiamen University, 38(5), 732-737 (in Chinese with English abstract).

Hu, J. Y., H. Kawamura, H. S. Hong, and W. R. Pan, 2000: Review on the upwelling in the Taiwan Strait studied by hydrographic analysis and numerical modelling. Submitted to 


\section{Progress in Oceanography.}

Huang, R. X., 1989: Upwelling in middle and north Taiwan Strait. Transactions of Oceanology and Limnology, (4), 8-12 (in Chinese with English abstract).

Huang, R. X., 1991: Structure of temperature and salinity in north central Taiwan Strait in spring and summer. Marine Sciences, (4), 53-56 (in Chinese with English abstract).

Hung, T. C., C. C. H. Tsai, and N. C. Chen, 1986: Chemical and biomass studies (1) Evidences of Upwelling off the southwestern coast of Taiwan. Acta Oceanographica Taiwanica, 17, 29-44.

Jan, S., C. S. Chern, and J. Wang, 1994a: A numerical study on currents in the Taiwan Strait during summertime. La Mer, 32, 225-234.

Jan, S., C. S. Chern, and J. Wang, 1994b: Influences of sea surface wind stresses on summertime flow pattern in the Taiwan Strait. Acta Oceanographica Taiwanica, 33, $63-80$ (in Chinese with English abstract).

Li, L., 1993: Summer upwelling system over the northern continental shelf of the South China Sea: a physical description. In Proceedings of the Symposium on the Physical and Chemical Oceanography of the China Seas. China Ocean Press, Beijing, 58-68.

Li, L., and D. Li, 1989: Summer hydrographic features of Channel west of Taiwan Shoals and the coastal upwelling. J. Oceanography in Taiwan Strait, 8(4), 353-359 (in Chinese with English abstract).

Sakaida, F., and H. Kawamura, 1992: Estimation of sea surface temperatures around Japan using the Advanced High Resolution Radiometer (AVHRR)/NOAA-11. $J$. Oceanography, 48, 179-192.

Sakaida, F., and H. Kawamura, 1996: HIGHERS -.T-The AVHRR-based higher spatial resolution sea surface temperature dataset intended for studying the ocean south of Japan. $J$. Oceanography, 52, 441-455.

Sakaida, F., J. Kudoh, and H. Kawamura, 2000: A-HIGHERS - The system to produce the high spatial resolution sea surface temperature maps of the Western North Pacific using the AVHRR/NOAA. J. Oceanography, 56, 707-716.

Wang, J., and C. S. Chern, 1992a: On the distribution of bottom cold waters in Taiwan Strait during summertime. La mer, 30, 213-221.

Wang, J., and C. S. Chern, 1992b: On the deflection of a rotational, baroclinic jet by an angular coast with application to the branching of currents southwest of Taiwan. Acta Oceanographica Taiwanica, 29, 18-33.

Weng, X. C., R. X. Huang, H. X. Liang, and H. Li, 1988: Physical oceanographic features. In A Comprehensive Oceanographic Survey of the Central and Northern part of the Taiwan Strait. China Science Press, Beijing, 138-188. (in Chinese).

Weng, X. C., Q. L. Zhang, T. Z. Yan, and C.M. Wang, 1992: Analysis of water masses in the middle and northern Taiwan Strait in spring and summer. Oceanologia et Limnologia Sinica, 23(3), 235-244 (in Chinese with English abstract).

Wu, B. Y., 1983: The current pattern and hydrologic character in the Taiwan Straits and its adjacent waters. Marine Science Bulletin, 2(4), 1-8 (in Chinese with English abstract).

Wu, Y. C., X. C. Weng, and Y. L. Yang, 1997: Analysis on causes of generation, evolution and decay process of upwellings off the western coast of Taiwan Strait. Studia Marina 
Sinica, 38, 53-59 (in Chinese with English abstract).

Xiao, H., 1988: Studies of coastal upwelling in western Taiwan Strait. Journal of Oceanography in Taiwan Strait; 7(2), 135-142 (in Chinese with English abstract).

Yan, T. Z., H. Y. Li, and G.Y. Yu, 1997: Numerical study on upwelling along the coast of Fujian II. Three dimensional numerical simulation of upwelling in Taiwan Strait. Acta Oceanologica Sinica, 19(5), 12-19 (in Chinese).

Zhang, G. R., J. Y. Hu, and J. Q. Chen, 1991: Numerical studies on upwelling in the southern Taiwan Strait. II. 3-dimensional numerical calculation of wind-driven upwelling. In Minnan-Taiwan Bank Fishing Ground Upwelling Ecosystem Study. China Science Press, Beijing, 127-133. (in Chinese with English abstract).

Zhang, X. B., J. Y. Hu, C. Y. Zhang, Z. Z. Chen, F. Q. Lin, H. X. Liang, and J. S. Hong, 2000: Multi-days variation of temperature and salinity in southern marginal area of Taiwan Shoal in August 1997. Journal of Oceanography in Taiwan Strait, 19(1), 89-94 (in Chinese with English abstract). 